\title{
PERIODIC HYPERSOMNIA, CONGENITAL ECTODERMAL DISORDERS AND MULTIPLE EXOSTOSIS
}

\author{
RUBENS REIMAO* - ARON DIAMENT**
}

\begin{abstract}
SUMMARY - A case of periodic hypersomnia in an 11-year-old feniale with the unique features of mental deficiency, incontinentia pigmenti, acanthosis nigricans and hereditary multiple exostosis (diaphysial aclasis) is reported. The clinical, polysomnographic and Multiple sleep Latency test features of this case with a follow up of seven years are consistent with a diagnosis of periodic (intermittent) excessive somnolence. The unique presentation, however, does differ from Kleine-Levin syndrome and suggests a relationship between the predominantly ectodermal, congenital disorders and the sleep-wake pattern dysfunction.
\end{abstract}

\section{Jlipersoonia periódica, malformacôes ectodérmicas e exostose múltiplu.}

RESUMO - Relata-se um caso de sonolência excessiva periódica acompanhada de hiperfagia, com inicio na segunda década, documentado clinicamente, em traçados polissonográficos de noite inteira e no teste das Latências Múltiplas do Sono. Apresenta características que o distinguem da sindrome de Kleine-Levin, a saber, a ocorrência no sexo feminino, deficiência mental, incontinência pigmentar, acantose nigricans e exostose mứtipla.

There are two well defined syndromes of periodic hypersomnia 1: menstrual cycle-related somnolence and the Kleine-Levin syndrome (KLS). The former is usually temporally linked with the menses; the latter, a rare condition, is generally limited to males in which the first episode of excessive sleepiness occurs in the second decade of life associated with hyperphagia. It supposedly results from hypothalamic or lymbic dysfunctions.

This report describes a case of periodic hypersomnia and hyperphagia, beginning in the second decade but clearly distinct from KLS, occurring in a female with mental deficiency, incontinentia pigmenti and multiple exostosis.

\section{CASE REPORT}

MRS, an 11-year-old female was referred to our clinic seven years ago, presenting periods of one to two weeks hypersomnolence that started 6 months previously. During these periods, the patient slent most of the day and night, waking only for toilet necessities and eating during which time sleepiness was still reported. In some of these periods she exhibited voracious eating but no inappropriate sexual behavior. She has been followed up for 7 years and the periods of hypersomnolence first noted every 3 to 4 months are now seen only yearly. Outside these periods she has adequate sleep. There is no relation between hypersomnolence and menstrual cycle. Her menses are irregular with intervals

Pediatric Neurology Unit (* Assistant; ** Head), Department of Neurology, Faculty of Medicine, University of São Paulo, and Sleep Disorders Center, Albert Einstein Hospital, São Paulo.

Departamento de Neurologia, Faculdade de Medicina da Universidade de Săo Paulo - Caina Postal 3461 - 01051 \$̊ Paulo SP - Brasil 
up to 6 months. There is consanguinity in the family and her grandfather had similar exostosis. The physical examination revealed incontinentia pigmenti with areas of hyperpigmentation on the 4 limbs and back. Acanthosis nigricans around the nose. Extention of the lett elbow limited. Neurological examination revealed mental deficiency with no focal signs. Fundus was normal. Psychological examination pcrformed twice confirmed IQ $=55$; no symptoms of depression. EEG, CT brain scan, brain nuclear magnetic ressonance and CSF were normal. Chromossomal study revealed normal $46 \mathrm{XX}$ with normal bands. Dermatoglyphic study was abnormal with $\mathrm{TRC}=33 ; \quad R=a t d=54^{\circ} ; \quad R w=32 \% ; \quad L=$ atd $=49^{\circ}$; $\mathrm{Rw}=28.4 \%$. Radiological examinations showed multiple, bilateral exostosis on the metaphysis of the distal femur, proximal tibia, distal left fibula, proximal right humerus. The ulnas were short. Left elbow was dislocated. Hand X-rays showed displasia of the pisiform bone. Bone age was 16 years for a chronological age of 14 . Skull films were normal . Two skin biopsies confirmed the diagnosis of incontinentia pigmenti and acanthosis nigricans. Muscle biopsy was normal. Laboratory tests including serum calcium and phosphorus, fasting morning blcod glucose, T3, T4, TSH, FSH, and cortisol were normal. Alkaline phosphatase was repeatediy elevated, from 522 to $770 \mathrm{U} / 1$ (normal values $60-220 \mathrm{U} / 1$ ). Urinary screening tests for inborn errors of metabolism were negative. Pelvic ultrasound examination revealed hynoplastic uterus and normal ovaries.

Two all-night polysomnographic (PSG) recordings were performed (Table 1) using standard criteria (16) including EEG, electrooculogram, submental and anterior tibialis eiectromyography, nasal and buccal thermistors, pneumogram and electrocardiogram. The monitoring was performed in periods with and without excessive daytime somnalence; both failed to show breathing or heart rate abnormality, or nocturnal myoclonus. The Multiple sleep Latency test (MLST) was performed twice according to standard criteria (13). During a period of basal non-hypersomnia, mean sleep latency was 16.2 min with no REM sleep detected. During a period of hypersomnia, mean sleep latency was $4.1 \mathrm{~min}$; no REM sleep detected.

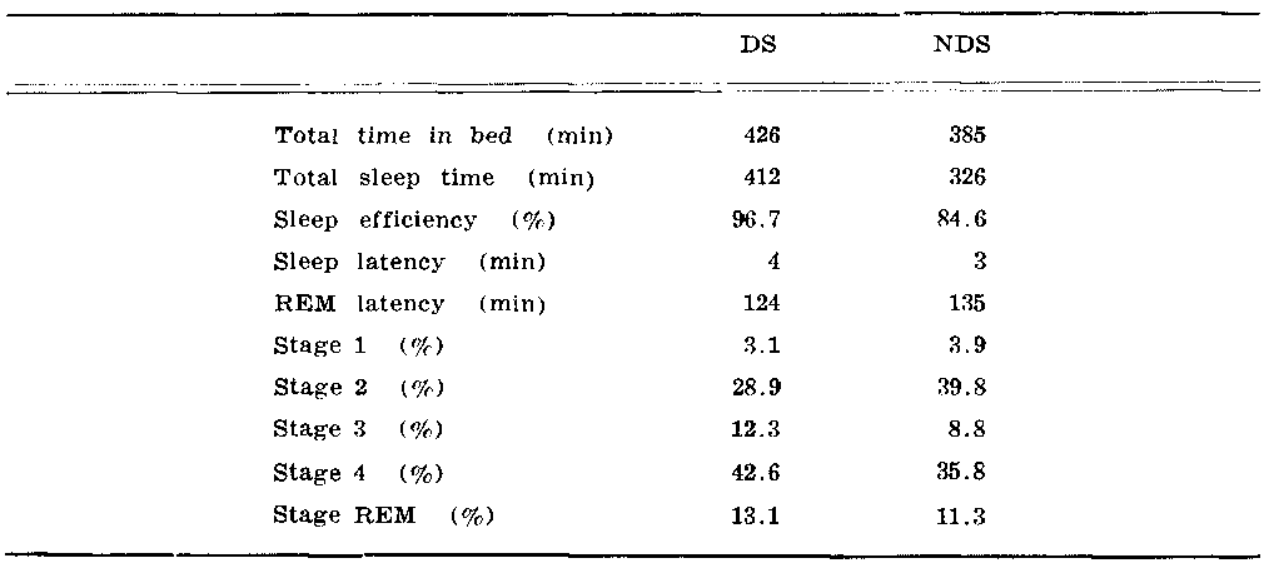

Table 1 - All-night polysomnographic data obtained during baseline non-excessive daytime sommolence period (NDS) and during a period with excessive daytime somnolence (DS).

\section{COMMENTS}

Excessive daytime sleepiness for days or weeks interspersed with asymptomatic periods of several days or weeks, commencing in the second decade of life accompanied by hyperphagia and usually limited to males are characteristic of KLS 3 . In most cases, the severity of such episodes decreases after some years to spontaneous remittance. This rare syndrome was described by Kleine in 1923 and Levin in 1929. Critchley in 1962 reviewed 31 cases in the literature and added 11 of his own. Since then, only a few patients showing symptoms beginning outside adolescence or occurring in females have been described $3,6,7,10$. Our patient has a few features resembling this syndromie, such as periodic hypersomnia and the age onset. However, in the literature which includes extensive reviews $3,12,14$ there are no cases with mental deficiency: multiple exostosis, incontinentia pigmenti and acanthosis nigricans. 
Incontirlentia pigmenti, or Bloch-Sulzberger syndrome, occurs almost exclusively in females and is accompanied by a wide range of ectodermal and mesodermal defects in two thirds of the patients. Among these, mental deficiency may be found. Acanthosis nigricans, another rare dermatosis, is characterized by hyperpigmentation and epidermic hypertrophy. Its juvenile form may be associated with several metabolic, endocrine or developmental abnormalities. It may occur in association with mental deficiency and hypothalamic or pituitary endocrinopathies. In few cases, a familial occurrence is encountered suggesting hereditary factors of still undetermined pattern.

The bone characteristics of our case are clinically and roentgenographically typical of multiple exostosis (diaphysial aclasis) $2,6,9,18,19,20$. In this rare disease, bone thickening and deformity occur during the most active growing period. The justaepiphysial regions of long bones, ribs, pelvis and scapulae are the most affected. Short stature but within normal limits 18 , bowing of the radius with ulnar wrist deviation and humero-radial joint subluxation are characteristic and were present in the patient here ciescribed. This disease is generally autosomal dominant but a few cases may arise by spontaneous mutation; there are no abnormalities in karyotype or band studies $\hat{\epsilon}$. On the other hand, multiple exostosis cases show essentially bone impairment alone with no skin pathology, mental deficiency or sleep-wake dysfunctions.

PSG and MSLT revealed excessive daytime sleepiness but failed to show sleep apnea, narcolepsy, nocturnal myoclonus or any other abnormalities. No depressive features were noted in the PSG, as suggested in one KLS case by Reynolds et al.17 in 1980. PSG recordings in KLS are few and with mixed results 8,10,12,15,17; some are normal while some show characteristics of much more commom disorders like sleep apnea or narcolepsy.

The occurence of periodic hypersomnia and mental deficiency suggest a neural dysfunction in the sleep-wake cycle system. A congenital malformative etiology is likely as the patient has other ectodermal dysplasias, consanguinity and no other apparent cause for mental deficiency.

\section{REFERENCES}

1. Association of Sleep Disorders Centers - Diagnostic classification of sleep and arousal jisorders. Sleep $2: 1,1979$.

2. Brooks AP, Wymne-Davies $R$ - A family with dyaphysed and peripheral dysostosis. J Med Genet 17:277, 1980 .

3. Critchley $\mathrm{M}$ - Periodic hypersomnia and megaphagia in adolescent males. Brain $85: 627$, 1962.

4. Duffy JB, Davidson $K$ - A female case of Kleine Lcvin syndrome. Br J Psychiat $114: 77,1968$.

5. Earle BV - Periodic hypersomnia and megaphagia (the Kleine-Levin syndrome). Psychiatr Quart 39:79, 1965.

6. Gardmer EJ, Shupe JL, Leone NC, Olson AE - Hereditary multiple exostosis: a comparative genetic evaluation in man and horses. $J$ Hered 66:318, 1975.

7. Gilbert GJ - Periodic hypersomnia and bulimia: the Kleine-Levin syndrome. Neurology $14: 844,1964$.

8. Green LN, Cracco $R Q$ - Kleine-Levin syndrome: a case with EEG evidence of periodic brain dysfunction. Arch Neurol 22:166, 1970.

9. Ho SU, Lipton HL - Hereditary multiple exostoses with myelopathy. Arch Neurol $36: 714,1979$.

10. Lavie P, Gadoth $\mathbf{N}$, Gordon $\mathbf{C R}$, Goldhammer $G$, Bechar $\mathbf{M}$ - Sleep patterns in Kleine-Levin syndrome. Electroenceph Clin Neurophysiol 47:369, 1979.

11. Lavie P, Klein E, Gadoth N, Bental E, Zomer J, Bechar M, Wajsbort J - Further observations on sleep abnormalities in Kleine-Levin syndrome: abnormat breathing pattern during sleep. Electroenceph Clin Neurophysiol 52:98, 1981. 
12. Messimy $\mathbf{R}$ - Itypersomnie périodique: le syndrome de Kleine-Levin et ses problemes: revue des cas récents. Int $J$ Neurol 15:119, 1981.

13. Mitler M - The Multiple Sleep Latency test as an evaluation for excessive somnolence. In Guilleminault C - Sleeping and Waking Disorders: Indications and Techniques. Addison-Wesley Publ, Menlo Park, 1982, pg 145.

14. OrJosky MJ - The Kleine-Levin syndrome: a review. Psychosomatics 23:609, 1982.

15. Plasse M, Joannard A, Maynard R, Jouk PS, Gilly R, Beaudoing A - Syndrome de Kleine-Levin. Pediatrie 32:601, 1982.

16. Rechtschaffen A, Kales $\Lambda$ - A Manual of Standardized Terminology. Techniques and Scoring System for Sleep Stages of Human Subjects. Brain Information Service/Brain Research Institute, University of California, Los Angeles, 1968.

17. Reynolds CF, Black RS, Coble P, Holzer B, Kupfer DJ - Similarities in EEG sleep findings for Kleine-Levin syndrome and unipolar depression. Am $J$ Psychiat 137:116, 1980 .

18. Shapiro F, Simon S, Glimcher MJ - Hereditary multiple exostosis, J Bone Joint Surg $61 \mathrm{~A}: 815,1979$.

19. Solomon L - Hereditary multiple exostosis. J Bone Joint Surg 45B:292, 1963.

20. Solomon L - Hereditary multiple exostosis. Am J Hum Cenet 16:351, 1964. 